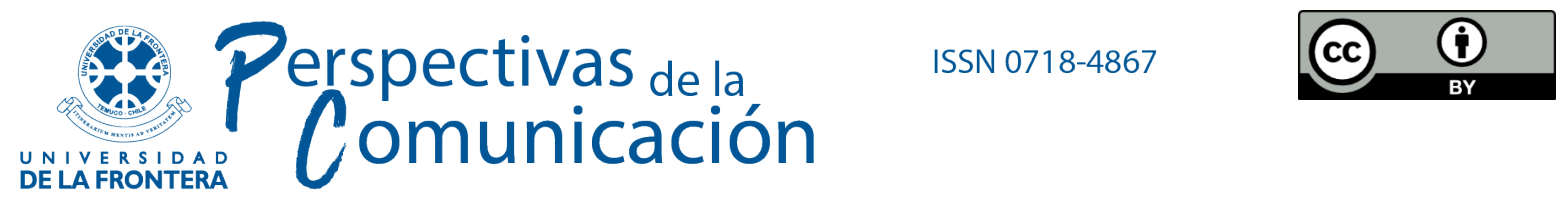

Artículo

\title{
ECONOMÍA POLÍTICA DE LA COMUNICACIÓN: DE SUS ORÍGENES A LA CONSOLIDACIÓN DEL CAMPO EN AMÉRICA LATINA
}

DOI: POR ASIGNAR

Dra. Bernadette Califano

CONICET, Universidad de Buenos Aires, Universidad Nacional de Quilmes, Buenos Aires, Argentina

bernacali@gmail.com

ORCID iD: https://orcid.org/o0oo-0002-5014-8359

Recibido el 2020-07-30

Revisado el 2021-04-30

Aceptado el 2021-05-01

Publicado el 2021-09-23

\section{Resumen}

Este artículo analiza los postulados centrales de las investigaciones que dieron origen a la Economía Política de la Comunicación (EPC), identificando a sus principales autores y contribuciones, con énfasis en los trabajos que permitieron consolidar el campo en América Latina. Se traza un recorrido que se remonta a mediados del siglo XX, cuando una serie de teóricos formados en los presupuestos de la economía neoclásica y la teoría marxista plantearon la necesidad de analizar los medios de comunicación como organizaciones industriales que producen y distribuyen mercancías. Así, comenzaron a indagar en torno de la especificidad económica de las industrias culturales y sus productos, y en las relaciones establecidas entre los Estados, las empresas de medios y las grandes corporaciones. A medida que las industrias del sector de la comunicación se expandieron y cobraron un peso relevante sobre la economía mundial, la EPC se consolidó como una de las aproximaciones centrales para el estudio del comportamiento económico de los medios, sus procesos productivos, formas de crecimiento y desarrollo, y las políticas públicas en el área.

Palabras clave: América Latina, economía política de la comunicación, industrias culturales, marxismo, teoría de la comunicación. 


\title{
POLITICAL ECONOMY OF COMMUNICATION: FROM ITS ORIGINS TO THE CONSOLIDATION OF THE FIELD IN LATIN AMERICA
}

\begin{abstract}
This article discusses the foundations that gave rise to the Political Economy of Communication (PEC), identifying its main authors and contributions, with emphasis on the investigations that allowed consolidating the field in Latin America. This paper traces a route that dates back to the mid-twentieth century, when a series of theorists trained in the assumptions of neoclassical economics and Marxist theory raised the need to analyze the media as industrial organizations that produce and distribute commodities. They began to inquire about the economic specificity of cultural industries and their products, and dealing into the relationships established between states, media companies, and large corporations. As the industries of the communication sector expanded and gained a relevant weight over the world economy, the EPC consolidated itself as one of the central approaches for studying the economic behavior of the media, its production processes, forms of growth and development, and the public policies in the area.
\end{abstract}

Keywords: Latin America, political economy of communication, cultural industries, Marxism, communication theory. 


\section{Introducción}

El objetivo de este artículo es analizar la trayectoria seguida por las investigaciones que dieron origen a la Economía Política de la Comunicación (EPC), identificando a sus principales autores y contribuciones, con énfasis en los estudios que permitieron consolidar el campo en América Latina.

Si bien la EPC es considerada una rama dentro de los estudios en comunicación, toma aportes fundamentales de la economía y de las ciencias políticas, junto con herramientas de análisis compartidas por la sociología y la historia.

Para analizar los inicios de la EPC es preciso referirse brevemente a los orígenes de la economía política, que nace en el siglo XVIII con el objetivo de explicar las causas de la aceleración del capitalismo. Los primeros trabajos se atribuyen a los economistas clásicos entre los que se hallaban Adam Smith, David Ricardo y Thomas Malthus- cuya preocupación central giraba en torno del estudio de los bienes materiales, su producción y distribución, con las consecuencias para el bienestar de las sociedades. Según la célebre metáfora del escocés Adam Smith ([1776], 1996), la conducta económica se basaba en el propio interés y el mercado actuaba como una "mano invisible" que habilitaba el desarrollo económico y la prosperidad general.

En el siglo XIX, con los trabajos de Karl Marx y Frederick Engels ([1845], 1982), se inició una crítica radical al sistema capitalista y a las desigualdades estructurales que conlleva. Hacia fines del siglo, un nuevo giro en el estudio de los temas económicos condujo la mirada hacia el microanálisis, colocando el acento en las preocupaciones individuales (Marx, [1859], 2008a; [1867], 2008b). Este enfoque neoclásico pasó luego a denominarse simplemente "economía". Si bien la economía neoclásica es la que predomina actualmente, la economía política continuó con ciertas aproximaciones conservadoras, con otras que focalizan en los factores institucionales y tecnológicos que influyen sobre los mercados, y con versiones críticas, radicales y marxianas. Éstas últimas constituyen los antecedentes principales cuando se alude a la tradición más representativa dentro de los estudios de la Economía Política de la Comunicación (Mosco, 2009; Wasko, 2005).

Hasta avanzado el siglo XX, los medios de comunicación y la cultura no habían sido objeto de análisis por parte de los economistas, fundamentalmente porque no contaban con un peso relevante sobre las economías nacionales. Además, operaban en mercados con 
características particulares, pues eran típicamente oligopólicos y se encontraban fuertemente regulados por controles públicos. El desarrollo de las industrias de la comunicación y su creciente contribución al Producto Bruto Interno (PBI) de los países condujo a prestar cada vez mayor atención a la economía y al funcionamiento de estas empresas.

Hacia la década de los años sesenta, los estudios sobre medios de comunicación se hallaban primordialmente influidos por la tradición de la Mass Communication Research. Estos trabajos se preocupaban por los efectos de los mensajes sobre las audiencias, antes que por los emisores y/o el contexto económico en el que dichos mensajes se producían, distribuían y consumían. El origen de la Economía Política de la Comunicación puede rastrearse en el cuestionamiento a estas miradas funcionalistas.

Los primeros teóricos del campo, formados en los presupuestos de la economía neoclásica y la teoría marxista, plantearon la necesidad de analizar los medios de comunicación como organizaciones industriales que producen y distribuyen mercancías. Así, comenzaron a indagar en torno de la especificidad económica de estas industrias y sus productos, en las particularidades de los bienes culturales, y en las relaciones establecidas entre los Estados, las empresas de medios y las corporaciones industriales.

A medida que las industrias del sector de la comunicación cobraron un peso cada vez más relevante sobre la economía mundial, se fueron consolidando las investigaciones de la EPC. Esto pudo observarse en la multiplicación de trabajos que comenzaron a indagar sobre la economía de los medios. Entre 1965 y 1988 se publicaron 351 artículos académicos focalizados en algún aspecto económico de la comunicación en revistas de primer nivel, como el Journal of Broadcasting and Electronic Media, Journalism and Mass Communication Quarterly y el Journal of Communication (Miller \& Gandy, 1991). Asimismo, surgieron las primeras publicaciones académicas especializadas, tales como el Journal of Media Economics creado en 1988. En la década de los años ochenta nació una sección estable para la Economía Política de la Comunicación dentro de la International Association for Media and Communication Research (IAMCR); en los noventa se creó un grupo de trabajo específico dentro de la Asociación Latinoamericana de Investigadores de la Comunicación (ALAIC); y en años posteriores se fundaron asociaciones de investigadores en la materia, tanto a nivel regional como local. 
Este artículo indaga en profundidad en las investigaciones que sentaron las bases para el desarrollo de la Economía Política de la Comunicación. En primer lugar, se analizan los trabajos pioneros publicados en países de América del Norte y Europa. A continuación, se describe la trayectoria de los investigadores y de las publicaciones que permitieron consolidar el campo en América Latina a lo largo de la segunda mitad del siglo XX. Asimismo, se propone una sistematización de las líneas de investigación principales a comienzos del siglo XXI y de los trabajos representativos de cada una de ellas en los países de la región. Por último, se brindan una serie de reflexiones sobre las preocupaciones y problemáticas específicas de las investigaciones enmarcadas en esta perspectiva.

\section{Las discusiones teóricas que dieron origen a la EPC}

Las primeras investigaciones de la Economía Política de la Comunicación se remontan a mediados del siglo XX y suelen agruparse por región. Entre los fundadores del campo se hallan Dallas Smythe y Herbert Schiller en América del Norte; Graham Murdock, Peter Golding y Nicholas Garnham en el Reino Unido; y Bernard Miège y Patrice Flichy en Francia. Estos investigadores insistieron en la denuncia del sistema comunicativo en el que se encontraban insertos y procuraron redefinir paradigmas, tanto en el marco de los organismos internacionales como en sus respectivos países con relación a la formulación de políticas de comunicación.

\subsection{La investigación norteamericana}

La tradición institucionalista y marxista de dos de los precursores de la EPC, Dallas Smythe y Herbert Schiller, influyó sobre gran parte de la investigación en los Estados Unidos.

Dallas Smythe, de origen canadiense, cursó sus estudios de grado y posgrado en economía en los Estados Unidos. Entre 1943 y 1948 trabajó en la Comisión Federal de Comunicaciones (FCC), organismo en el que dirigió tareas pioneras en materia de televisión, asignación de espectro radioeléctrico y telefonía. En 1948 comenzó a investigar en la Universidad de Illinois, donde dictó los primeros cursos de posgrado sobre economía política de la comunicación. A principios de la década del sesenta, publicó el artículo titulado "On the Political Economy of Communications" (Smythe, 1960) donde presentaba una de las primeras aplicaciones de la economía política al campo comunicativo. Sin emplear aún la terminología marxista que aparecería en sus trabajos posteriores, este artículo representó 
un quiebre dentro de las investigaciones que dominaban por entonces el estudio de los medios de comunicación de masas.

En este trabajo, Smythe señalaba que el propósito de la Economía Política de la Comunicación residía en estudiar las políticas elaboradas por agencias especializadas, sus efectos y las estructuras que asumen en determinados entornos sociales. Por medio de extrapolar los grandes intereses de la economía política al campo comunicacional -cómo asignar recursos escasos a fin de satisfacer ciertas necesidades mientras otras quedan insatisfechas-, el investigador enfatizaba en la necesidad de que la EPC se abocase a responder tres preguntas centrales: qué bienes y servicios comunicacionales, para quién y cómo proveerlos. Estas preguntas debían organizarse en torno de tres grandes áreas de políticas públicas: a) la producción, por medio del análisis de políticas sobre calidad, cantidad y acceso a bienes y servicios comunicacionales; b) la asignación y distribución de recursos, referida a la disponibilidad física de dichos bienes y a las políticas sociales de equidad o inequidad en su distribución; c) el capital, la organización y el control de estos bienes y servicios. Insistía en el hecho de que el análisis de los medios de comunicación debía basarse en la aplicación de herramientas provenientes de las ciencias políticas y, fundamentalmente, de la economía.

Smythe, junto con otros investigadores estadounidenses, y en particular con su compañero en la Universidad de Illinois Herbert Schiller, continuaron realizando trabajos académicos y dictando cursos sobre economía política de la comunicación en la década de 1960. Así, en 1969 Schiller publicó el libro "Mass Communication and American Empire” [versión en español: "Comunicación de masas e imperialismo yanqui" (Shiller, 1976)], donde analizaba, desde una perspectiva crítica, la relación existente entre el complejo militar-industrial de los Estados Unidos y las industrias de la comunicación. El autor argumentaba cómo, desde la Segunda Guerra Mundial, el gobierno norteamericano había centrado su atención en los medios de comunicación de masas con el propósito de propagar el "modo de vida americano" y la ideología capitalista hacia el resto del mundo, a fin de sentar las bases de una nueva forma de dominación cultural. Para ello, promovía la liberalización de las comunicaciones a nivel mundial y pregonaba a favor de la doctrina del "libre flujo de la información", que sería defendida en el marco de los debates internacionales que se produjeron en la década de los años setenta en el seno de la Organización de las Naciones Unidas para la Educación, la Ciencia y la Cultura (UNESCO). 


\subsection{La investigación británica}

En esta primera época los principales trabajos europeos se preocuparon por integrar la investigación en comunicación dentro de las tradiciones teóricas neo-marxistas (Mosco, 2009). En este sentido, los británicos Graham Murdock y Peter Golding publicaron "For a political economy of mass communications" (1973), donde afirmaban que el punto de partida de la disciplina debía ser el reconocimiento de que los medios masivos son, ante todo, organizaciones industriales y comerciales que producen y distribuyen mercancías. Subrayaron, además, que dicha producción mercantil conlleva un rol ideológico, ya que los medios difunden ideas acerca de las estructuras económicas y políticas de la sociedad. Así, sostuvieron que el análisis de los medios de comunicación requiere de un doble acercamiento conceptual: no solo en términos económicos, sino también políticos.

Murdock y Golding (1973) argumentaron que este enfoque se contraponía con los análisis hechos hasta entonces acerca del rol ideológico de los medios, al que acusaban de "abstracto y esquemático" (p. 207). Específicamente, criticaron la concepción althusseriana pues señalaban que no era suficiente con aseverar que los medios de comunicación son parte de los “aparatos ideológicos del Estado" (Althusser, 1970), sino que era preciso demostrar el modo en que la ideología se ejercía en la práctica concreta, y cómo los medios masivos resultaban centrales para la legitimación de las complejas relaciones de poder en las sociedades capitalistas.

Si bien Marx no desarrolló específicamente el papel de los medios de comunicación en las sociedades capitalistas, en su obra se identifican algunos temas clave para su estudio. Uno de ellos es la noción de que quienes dominan los "medios de producción material" en las sociedades controlan a su vez los "medios de producción mental", por lo tanto, mientras sean la clase dominante, dominan la distribución y circulación de ideas de su tiempo (Marx \& Engels, 1982). En "Contribución a una crítica de la economía política”, publicado originalmente en 1859, Marx (2008a) afirma que "el modo de producción de la vida material determina [bedingen] el proceso social, político e intelectual de la vida en general" (p. 4-5). Esto fue muchas veces entendido como un determinismo económico en Marx. No obstante, Murdock y Golding (1973), junto con Williams (1973) y otros, sostienen que la noción de determinación y condicionamiento es utilizada en el sentido amplio de "fijación de límites".

Varios intelectuales marxistas, enmarcados dentro de la Escuela de Frankfurt y de los estudios culturales británicos, se interesaron en el análisis específico de la relación entre la 
base económica y la superestructura cultural. Si bien Murdock y Golding reconocían la importancia de estos trabajos, les reprochaban su mayor énfasis en lo cultural que en la base económica. Los autores argumentaban que era preciso examinar, en una "lógica de la sucesión”, primero las estructuras económicas y luego sus productos culturales:

Sólo situando a los productos culturales dentro del nexo de los intereses materiales que circunscriben su creación y distribución es como se pueden explicar plenamente su gama y su contenido. (Murdock \& Golding, 1981, p. 48)

En “Capitalismo, comunicaciones y relaciones de clase”, publicado originalmente en 1979, Murdock y Golding realizaron un esfuerzo teórico por situar el enfoque de la Economía Política de la Comunicación dentro del marco general de la teoría crítica. En este texto insisten en realizar análisis empíricos para examinar en qué medida los propietarios de las empresas de medios otorgan prioridad a la economía y de qué forma esto influye sobre sus productos:

Lejos de ser «eventuales», las cuestiones de los recursos y de las ganancias y pérdidas desempeñan un papel protagónico en la estructuración, tanto de los procesos como de los productos de la producción televisiva, incluyendo la fabricación de noticias y de temas corrientes. (Murdock \& Golding, 1981, p. 30).

En su trabajo inicial, los autores sostuvieron que la variedad de encuadres interpretativos, ideas y argumentos que las personas utilizan para dar sentido y significado a sus vidas cotidianas, depende en gran medida de lo que producen los medios de comunicación. El problema es que "los encuadres ofrecidos se hallan necesariamente articulados con el nexo de intereses que los produce y, en este sentido, toda información es ideología" [traducción propia] (Murdock \& Golding, 1973, p. 226). Estos conflictos de intereses son el punto crucial del sistema, afirman los investigadores, porque "la información es una mercancía para ser empacada, distribuida y vendida bajo cualquier aspecto y contexto que garantice la supervivencia comercial” [traducción propia] (p. 227).

Siguiendo con los trabajos de este período fundacional de la disciplina, algunos años más tarde otro investigador de origen británico, Nicholas Garnham, publicó "Contribution to a political economy of mass-communication”. En sintonía con el planteo de Williams (1973, 1977), Garnham (1979) argumentaba a favor de revisar, dentro de la teoría cultural, la fórmula marxista de la base y la superestructura, y redefinir a las fuerzas productivas en el 
contexto del desarrollo de los modernos sistemas de comunicación de las sociedades capitalistas. El autor proponía elaborar una economía política de los medios masivos dentro del marco más amplio de la economía política de la cultura- que se abocara al estudio de los modos de producción y reproducción cultural específicos de esta fase histórica del desarrollo capitalista. En este sentido, formulaba críticas a las perspectivas marxistas que en el estudio de los medios de comunicación no habían logrado analizar adecuadamente la relación entre lo económico y lo ideológico. Según el autor, los investigadores caían en explicaciones reduccionistas, ya sea porque concebían a los medios como herramientas ideológicas de la clase dominante, a través de la propiedad directa o el control del Estado (Althusser, 1967, 1970; Hall, 1977; Miliband, 1977), o porque destacaban en exceso la función económica de los medios (Smythe, 1977).

En dicho trabajo, Garnham tomaba partido a favor de su colega Graham Murdoch en el debate teórico que había ocurrido algunos años antes con Dallas Smythe. La controversia giraba en torno de los "agujeros negros" hallados en la teoría marxista para su aplicación al campo de la comunicación. Smythe había publicado el artículo "Communications: blindspot of Western Marxism" (1977), donde sostenía que aún no se había desarrollado una teoría materialista de la comunicación de masas y acusaba al marxismo occidental -especialmente al europeo- de dicho vacío conceptual. El autor criticaba a los investigadores por haber analizado a los medios como parte de la superestructura ideológica, olvidándose de la base económica, y argumentaba que la economía política de los medios masivos debía basarse fundamentalmente en un análisis de su forma mercantil, pues su función crucial no consistía en "vender ideología” a los consumidores sino "audiencias" a las empresas publicitarias. Así, proponía situar a la economía en el centro del análisis cultural del marxismo.

Graham Murdock (1978) le respondió al año siguiente y su artículo fue publicado junto a un nuevo texto de Smythe (1978) en la revista Canadian Journal of Political and Social Theory. Este debate contribuyó en gran medida para que la Economía Política de la Comunicación profundizara en sus fundamentos teóricos y definiera epistemológicamente su enfoque.

\subsection{La investigación francesa}

Los primeros trabajos realizados en Francia en el campo de la EPC se distinguen de los enfoques anteriormente descritos porque se abocan al análisis empírico de la economía de los medios y la mercancía cultural, sin colocar tanto el acento en cuestiones ideológicas. Las investigaciones principales se agruparon en torno del Groupe de Recherches sur les Enjeux 
de la Communication (GRESEC), fundado en 1978 en la Universidad de Stendhal-Grenoble por el investigador Bernard Miège, quien fuera su director hasta el año 2002.

También se destaca, en esta línea, el trabajo de Patrice Flichy (1980), quien examinó la especificidad económica de las industrias culturales y sus productos, y distinguió entre el sector de la edición y el de flujo (radiodifusión). Se trata de uno de los primeros investigadores en subrayar la incertidumbre acerca de la valorización de las mercancías culturales y la aleatoriedad de la demanda.

Miège (1987) profundizó en los aportes de Flichy distinguiendo entre tres tipos de producción: la no capitalista, la capitalista y el trabajo productivo cultural. Su investigación focalizó en el modo en que se estructuran las industrias de la comunicación y en los procesos de trabajo y valorización de los productos culturales que las constituyen. Hizo hincapié en las diferencias dentro de las industrias culturales y analizó sus "lógicas sociales" de funcionamiento, que incluían la producción editorial, de flujos, de información escrita, de entretenimiento en directo y de información electrónica. Estas lógicas se combinaban entre sí para conformar tres modelos: de información editorial, de flujo y escrita. El trabajo de Miège y su equipo enfatizó en que la producción cultural industrializada no escapaba a las reglas de la economía capitalista.

La línea de investigación francesa influyó sobre los trabajos de reconocidos investigadores españoles en el campo de la Economía Política de la Comunicación, entre los que se hallan Enrique Bustamante, experto en economía y sociología de las industrias culturales de la Universidad Complutense de Madrid, y Ramón Zallo y Juan Carlos Miguel de Bustos, ambos catedráticos del área de Comunicación Audiovisual en la Universidad del País Vasco. Los trabajos de estos académicos tuvieron repercusión, a su vez, sobre la producción de la EPC en América Latina, fundamentalmente hacia fines del siglo XX y a comienzos del XXI.

\section{La perspectiva latinoamericana de la EPC}

La perspectiva latinoamericana de la Economía Política de la Comunicación surge vinculada a las luchas político-económicas y de liberación nacional, en diálogo con las llamadas "teorías de la dependencia" o del "imperialismo cultural”, luego de la Segunda Guerra Mundial. Si bien las líneas de investigación norteamericana y europea no tuvieron una influencia directa en su génesis, sus contribuciones fueron luego incorporadas. 
Desde sus inicios, esta perspectiva se ha caracterizado por el trabajo de expertos e investigadores comprometidos políticamente con el cuestionamiento de las relaciones de poder y las desigualdades en materia comunicacional, con los movimientos sociales por la democratización de las comunicaciones y con la formulación de políticas de medios.

En este sentido, la EPC puede ser concebida en su triple faz de "enfoque, campo y comunidad cultural”, según Bolaño, Narváez y Lopes (2014). Como enfoque, constituye una alternativa epistemológica que construye su objeto (los medios e industrias de la comunicación) desde su inserción dentro del desarrollo del capitalismo. En tanto campo, agrupa a un conjunto de investigadores "para quienes este enfoque representa una posibilidad real de interpretación y transformación de las relaciones comunicativas en las sociedades actuales" (p. 521). Y, en tanto comunidad académica y cultural, se nuclea en organizaciones que le permiten proyectarse a nivel internacional como interlocutores del campo anglosajón.

Entre los centros de investigación pioneros que contribuyeron con la consolidación de los trabajos en el campo se destaca la creación del Instituto Latinoamericano de Estudios Transnacionales (ILET), que reunió a un conjunto de intelectuales sudamericanos exiliados en México en el contexto de gobiernos militares en varios países de la región. El ILET fue fundado por los chilenos Juan Somavía y Fernando Reyes Matta en 1975. Su división de Comunicación y Desarrollo se transformó en el área más dinámica, entre cuyos investigadores se encontraban Diego Portales (Chile), Rafael Roncagliolo (Perú), Luis Ramiro Beltrán (Bolivia), Gregorio Selser, Héctor Schmucler, Nicolás Casullo y Alcira Argumedo (Argentina), además de Noreene Janus (Estados Unidos) y Cees Hamelink (Holanda). Contó, asimismo, con la asesoría de un comité académico integrado por Herbert Schiller (Estados Unidos), Armand Mattelart (Bélgica), Luis Gonzaga Motta (Brasil) y Oswaldo Capriles (Venezuela), entre otros. La agenda de investigación del ILET se enfocó en el estudio de los medios de comunicación transnacionales, en los procesos de producción y consumo cultural, en la industrialización transnacional de la cultura y las comunicaciones, y en la denuncia de la dependencia cultural (Reyes, 1977; Somavía, 1978). El organismo tuvo un peso relevante en el debate internacional por un nuevo orden económico e informativo, con el que sus investigadores demostraron un fuerte compromiso político e intelectual (Altamirano, 2021). En particular, su cofundador, Juan Somavía, fue uno de los especialistas que integró la llamada "Comisión MacBride" y contribuyó, con sus participaciones a nivel internacional, con la consolidación del ILET como un actor clave para el análisis de la dependencia cultural y de los flujos informativos internacionales. En 1977 se creó en Chile 
el Centro de Indagación y Expresión Cultural y Artística (CENECA), un instituto que fue referente para la investigación en temas de industrias culturales, cultura de masas y comunicación para el desarrollo. En una línea afín, uno de los integrantes del ILET, Rafael Roncagliolo, fundó en 1983 el Instituto para América Latina (IPAL) en Perú, enfocado en la ejecución de investigaciones político-económicas sobre los medios de comunicación, las nuevas tecnologías y las prácticas culturales alternativas.

\subsection{Los comienzos de la investigación en América Latina}

La década de los años sesenta fue crucial para el desarrollo de la Economía Política de la Comunicación en Latinoamérica, con una corriente importante que surgió en respuesta a las teorías de la modernización originadas en los Estados Unidos, bajo la influencia del paradigma contestatario de la dependencia, en el contexto del movimiento global por la descolonización.

En esta época se organizaron múltiples debates intergubernamentales en el seno de la UNESCO. Los Estados que integraban el Movimiento de Países No Alineados (MPNA) comenzaron a reclamar por un Nuevo Orden Económico Internacional (NOEI), como primer paso para revertir la dependencia económica de los países centrales y lograr también la independencia en el plano cultural. Denunciaron el monopolio que ejercían unas pocas agencias internacionales de prensa de los países desarrollados sobre la circulación de la información a nivel mundial y exigieron la instauración de un Nuevo Orden Informativo Internacional (NOII). Argumentaban que la circulación de la información no solo tenía que ser "libre", como proponía el discurso diplomático occidental, sino también "equilibrada". Se organizó una comisión de estudio sobre los problemas que afectaban a la comunicación a nivel global, presidida por Sean MacBride e integrada por representantes de distintos países. En la $21^{\circ}$ Conferencia General de la UNESCO en 1980, la mencionada comisión presentó un informe donde formulaba una serie de recomendaciones para crear un Nuevo Orden Mundial de la Información y la Comunicación (NOMIC) que acabara con los desequilibrios y desigualdades en materia de medios y sistemas de información.

El NOMIC reunió a varios expertos en Economía Política de la Comunicación de diversas partes del mundo, quienes elaboraron análisis de políticas específicas y balances de estos debates. Sin embargo, los gobiernos neoconservadores, que triunfaron en los países centrales hacia la década de los años ochenta, le quitaron su apoyo a la UNESCO para implementar el informe e iniciaron campañas de prensa con el fin de sabotearlo. El auge de 
las ideas neoliberales a nivel mundial supuso, además, que desapareciera el contexto político que había permitido su desarrollo (cfr. Argumedo, 1987; MacBride, 1980; Roncagliolo, 1983; entre otros).

En forma paralela a este debate, la UNESCO propuso promover las primeras Políticas Nacionales de Comunicación (PNC) en la mayoría de los países de llamado "tercer mundo". Esta idea se enraizaba con el progresivo acercamiento del organismo a los problemas comunicacionales vinculados con el desarrollo social y cultural, y con una concepción del Estado como un actor central para formular y aplicar políticas. Se partía de entender que de nada servía democratizar las relaciones internacionales en materia de comunicación si internamente se vivían situaciones inequitativas, como en el caso de varios países latinoamericanos que se encontraban gobernados por regímenes militares (cfr. Beltrán, 1974; Exeni, 1998).

Desde los años sesenta comenzaron a publicarse en América Latina una serie de investigaciones que realizaban diagnósticos acerca de la situación por la que atravesaban los medios de comunicación. Bajo la influencia de la teoría crítica, estos trabajos denunciaban las relaciones existentes entre la propiedad de los medios y la difusión de cierta ideología asociada a los sectores de poder, la concentración económica y geográfica de las empresas de medios de comunicación, y la dependencia tanto tecnológica (importación de equipos) como de contenidos (programas para la televisión latinoamericana).

Recién hacia los años setenta comenzó a redefinirse el rol del Estado, el que dejó de ser visto como un instrumento de dominación de clase, "cómplice" de los sectores dominantes, para ser entendido como un espacio de articulación de poder y un posible regulador frente a situaciones inequitativas, que lo habilitaban para plantear políticas en el área de la comunicación.

En esta línea, el filósofo venezolano Antonio Pasquali publicó en 1964 el libro "Comunicación y cultura de masas" (1976). Se trataba de un análisis que, si bien no descartaba la tradicional investigación en comunicación acerca de los mensajes y sus efectos, ponía el acento en la incidencia del poder en la estructuración de los contenidos mediáticos. Se proponía “desmontar la estructura del emisor" en la convicción de que el diagnóstico acerca de la conformación de la propiedad de los medios y su vinculación con otras áreas de poder económico y político era un instrumento idóneo para denunciar las características de 
los mensajes. La comunicación era entendida más como un problema de poder económico que de análisis semiológico de los mensajes, y el autor sugería partir de la propiedad y el poder como complementarios de otras formas de análisis (Graziano, 1997).

En esta época, apareció en Chile el renombrado trabajo de Ariel Dorfman y Armand Mattelart, "Para leer al Pato Donald" (2002), en el que los investigadores analizaban, desde un enfoque crítico, una serie de historietas infantiles publicadas por la Walt Disney Company. Su estudio permitió denunciar la dominación y colonización cultural común a todos los países latinoamericanos, demostrando que ésta se hallaba presente incluso en las revistas destinadas al público infantil: "las revistas infantiles no escapan, por lo tanto, a la dominación que funda todas las dominaciones sociales verticales en una sociedad" (Dorfman \& Mattelart, 2002, p. 21). Según Héctor Schmucler, quien escribió el prólogo de la obra, su valor fundamental residía en la indagación de la estructura del relato "para mostrar el universo de connotaciones que desencadena y que se instala en un nivel superior de significación ocupando el lugar fundamental en la comprensión del mensaje" (p. 6). Siguiendo a los autores, las historietas norteamericanas importadas por los países dependientes junto a otros objetos de consumo no serían solo la manifestación simbólica de la cultura capitalista sino también uno de los vehículos para la difusión y reproducción de la ideología burguesa, así como para la persistencia de la dominación cultural.

En una línea similar, los investigadores Luis Ramiro Beltrán y Elizabeth Fox de Cardona publicaron "Comunicación dominada: Estados Unidos en los medios de América Latina" (1980), donde constataban que, pese a la eliminación del colonialismo formal, la dominación cultural seguía presente y se llevaba a cabo a través de los medios de comunicación.

La investigación en Venezuela también contó con publicaciones tempranas que analizaron los vínculos entre el Estado y los medios de comunicación. El trabajo de Oswaldo Capriles (1976) examinó la concentración de la propiedad de los medios, la creciente inversión publicitaria en prensa, radio, televisión y cine, y los vínculos tendidos entre el sector público estatal, los anunciantes, las agencias publicitarias y las asociaciones de medios privados. Al igual que otros investigadores, insistía en la denuncia de la dependencia política y cultural frente a los medios privados en un contexto de capitalismo dependiente.

En la Argentina, Héctor Schmucler fue uno de los primeros intelectuales en abordar el campo de estudios de la comunicación, influenciado por la Escuela de Frankfurt y la teoría 
de la dependencia, luego de su desprendimiento de la semiología tradicional. Otro investigador destacado fue Heriberto Muraro, quien publicó "Neocapitalismo y comunicación de masa" (1974), donde planteó una crítica al sistema de medios masivos bajo control de empresas monopolistas como uno de los principales instrumentos de penetración cultural e ideológica en América Latina. Su trabajo buscaba “explicitar los nexos existentes entre los objetivos y la ideología de las instituciones características del neocapitalismo y la estructura y contenido de los medios de comunicación de masa” (p. 13). Se centraba en el análisis de la industria televisiva a partir de la década del cuarenta y analizaba las teorías de la manipulación comunicacional a fin de mostrar de qué forma era posible conceptualizar las operaciones ideológicas de los medios sobre el público. Sus investigaciones sobre las relaciones de propiedad de los medios en América Latina y, en particular, en la Argentina, fueron publicadas por la revista Crisis (Muraro, 1973a, 1973b). El autor continuó indagando acerca de los vínculos entre la comunicación y la economía en la década de los años ochenta, con la publicación de una serie de trabajos compilados en el libro "Invasión cultural, economía y comunicación” (Muraro, 1987).

En la misma línea afín al campo de la EPC, Margarita Graziano (1974) trabajó sobre la configuración del sistema de medios en la Argentina. La autora denunció, en sintonía con otras investigaciones latinoamericanas, el alto grado de concentración económica de la propiedad de los medios -en manos de unas pocas empresas vinculadas con intereses industriales, comerciales, agrícolas y con los círculos políticos- y la interdependencia existente entre estos intereses y el capital extranjero, en sus diversas formas: inversiones directas, control del mercado internacional de programas, equipos o materias primas, publicidad e influencia en el suministro de información a través de las grandes agencias de noticias.

La relevancia de la perspectiva latinoamericana en su etapa de consolidación reside en haber aportado datos tempranos sobre la estructura económica de los medios de comunicación que evidenciaron su condición empresarial y su matriz ideológica, así como el rol del Estado en estos procesos. La mayoría de los investigadores estuvieron políticamente comprometidos con las luchas por la democracia mediática, con los movimientos sociales por la democratización de las comunicaciones, con un nuevo orden económico e informativo, y con la posibilidad de transformar las prácticas comunicacionales. El ejercicio de esta praxis - que supone la unidad de investigación y acción (Mosco, 2009) - ha caracterizado el enfoque de la economía política crítica latinoamericana. Los trabajos que 
aquí reseñamos contribuyeron con el análisis del desarrollo y la consolidación del sistema televisivo en la región, con la caracterización de las relaciones tendidas entre el poder político y los empresarios mediáticos, y con el estudio de las políticas regulatorias.

\subsection{Las líneas de investigación desde los años 90}

Desde entonces han sido numerosos los trabajos que han abordado el estudio de los sistemas de medios de comunicación en América Latina desde la perspectiva de la EPC. Las políticas neoliberales en la década del noventa, que incluyeron medidas de apertura comercial, procesos de privatización, liberalización de los mercados, desregulación y re-regulación, alcanzaron al sector de los medios de comunicación. Ello fomentó la concentración de la propiedad y la mercantilización del sector comunicacional. A su vez, permitió la revitalización de las investigaciones en el campo, enfocadas ya no en el análisis ideológico de los mensajes a partir del estudio de la propiedad de los medios sino en las dinámicas económicas involucradas en la producción de las industrias culturales:

Si como señalara oportunamente Muraro durante gran parte de la década del 70 existió una fuerte tendencia a realizar una aproximación instrumental a la economía de las industrias culturales con el objetivo de analizar la matriz ideológica de los mensajes televisivos a través del análisis de propiedad, a partir de los 90 aparece y se consolida una corriente de estudios que busca comprender las dinámicas económicas involucradas en la producción cultural. Por supuesto que esto no supone abandonar el estudio de las relaciones de poder vinculadas a la producción cultural, pero ésta deja de estar subordinada a ser meramente un factor de reproducción ideológica. (Becerra \& Mastrini, 2006, p. 121).

El impulso a la investigación dentro del campo de la EPC en América Latina fue acompañado por la creación de asociaciones de investigadores a nivel regional y nacional. Así, en 1992 se creó en Brasil el Grupo de Trabajo (GT) Economía de las Comunicaciones, dentro de la Sociedad Brasilera de Estudios Interdisciplinarios de la Comunicación (INTERCOM), y en la misma década se fundó un GT específico dentro de la Asociación Latinoamericana de Investigadores de la Comunicación (ALAIC). En 2002 nació la Unión Latina de Economía Política de la Información, la Comunicación y la Cultura (ULEPICC), asociación que ha mantenido una sostenida actividad desde entonces y que cuenta con los capítulos nacionales Ulepicc-Brasil y Ulepicc-España, además de socios en la mayoría de los países de América Latina, Francia, Portugal e Italia. También se destaca la creación del Grupo de Investigación de Economía Política de la Comunicación, dentro de la Asociación Mexicana de Investigadores de la Comunicación (AMIC); el impulso dado a estos temas desde el Centro Internacional de Estudios Superiores de Periodismo para América Latina (CIESPAL), en 
particular a partir de la fundación de la revista Chasqui en 1972; y la creación de grupos específicos de trabajo dentro del Consejo Latinoamericano de Ciencias Sociales (CLACSO). El diálogo e intercambio a nivel internacional se fomentó, asimismo, con la coordinación latinoamericana de la sección de Economía Política de la Comunicación de la International Association of Media and Communication Research (IAMCR) ${ }^{1}$.

Han sido múltiples y variadas las líneas de investigación abocadas al estudio de los problemas estructurales en el continente desde la perspectiva de la EPC. Aquí procuramos identificar y sistematizar las problemáticas principales que han concitado la atención de los investigadores de la región.

Un primer gran enfoque se vincula con la necesidad, evidenciada a lo largo de las últimas décadas, de seguir afianzando la teoría, la epistemología y los métodos de la Economía Política de la Comunicación (Bolaño, 2012; Bolaño \& Mastrini, 2002; Bolaño, Mastrini \& Sierra, 2005; Haussen \& Brittos, 2009; Herscovici, 1995; Marques, 1993; entre otros), para adaptarlos a las realidades cambiantes a las que la investigación busca responder.

Una segunda línea de trabajo, probablemente una de las más prolíficas desde la década de 1990, se vincula con el análisis de las políticas de comunicación y cultura, tanto a nivel nacional como regional. Ello incluye el estudio de las regulaciones para las industrias culturales y los medios de comunicación, junto con las estrategias de los múltiples actores intervinientes en los procesos de elaboración de políticas públicas, en particular las empresas y los grupos mediáticos.

En esta línea podemos mencionar las publicaciones colectivas dirigidas por Crovi (1995) acerca del desarrollo de las industrias audiovisuales en México y Canadá, las coordinadas por Mastrini y Bolaño (1999) sobre los conglomerados de medios en América Latina, y las compiladas por Capparelli (1999) y Albornoz (2000) en torno de las transformaciones experimentadas por la industria televisiva del MERCOSUR. Sobre el bloque regional se

${ }^{1}$ El investigador mexicano Rodrigo Gómez García coordina la sección de la EPC de la IAMCR desde 2014, de la cual fue previamente vicecoordinador.

Perspectivas de la Comunicación - Vol. 14 - No 2 - 2021 - pp. 57-94

Universidad de la Frontera - Chile 
destacan, asimismo, los trabajos de Getino (2000) acerca de las industrias culturales, los de Jambeiro (2000) sobre la regulación de la televisión, y el de Monje (2013) sobre las políticas públicas de radio y televisión implementadas entre 1991 y 2007. Una mirada comparada sobre las políticas de comunicación de los gobiernos autodenominados 'progresistas' en el siglo XXI se encuentra en Badillo, Mastrini y Marenghi (2015). Los trabajos coordinados por Sel (2010) y Sierra Caballero y Vallejo (2017) también aportan análisis específicos en esta línea.

A la hora de examinar las investigaciones por país sobre políticas de comunicación, la producción resulta muy numerosa. En el caso de la Argentina se destacan los tempranos trabajos de Getino (1995) sobre las industrias culturales, donde el autor analiza tanto la dimensión económica como la necesidad de implementar políticas públicas que promuevan el desarrollo del sector. Una mirada integral y diacrónica sobre la regulación de medios, desde el nacimiento de la radio en 1920 hasta el año 2007, se halla en libro editado por Mastrini (2009). En una línea similar, el trabajo de Califano (2014) analiza las políticas audiovisuales para la televisión abierta, con sus antecedentes desde el nacimiento de la televisión en el país hasta la década de 1990, con foco en el proceso de privatización de los canales televisivos en el contexto neoliberal. Varias investigaciones han abordado el estudio de las políticas de comunicación en esta etapa: Mastrini (2013) enfatiza sobre el desarrollo de la televisión abierta y de pago durante los gobiernos de Carlos Menem (1989-1999), y Marino (2012) lo hace sobre la televisión por cable y el cine. Las políticas de las primeras décadas del siglo XXI también fueron sistemáticamente abordadas desde la mirada de la EPC (Baladrón, 2007; Califano, 2009; Mastrini \& Becerra, 2017; entre otros). A lo largo de los últimos años, los análisis se orientaron hacia el estudio de las políticas audiovisuales juntamente con la regulación de las telecomunicaciones y las tecnologías de información y comunicación, en el marco del proceso más amplio de convergencia entre sectores (Becerra, 2015; Bizberge, 2017; Califano, 2017, 2019).

En Brasil, el Grupo de Trabajo Economía de las Comunicaciones dentro de INTERCOM fue uno de los más prolíficos en la publicación de investigaciones sobre políticas de comunicación y cultura. De igual modo, la creación del boletín EPTIC, luego devenido en portal y revista académica, otorgó un fuerte impulso a la investigación en este campo, con César Bolaño, Valerio Brittos y Ruy Sardinha Lopes como algunos de sus principales referentes. En esta línea, los trabajos compilados de Ramos y Dos-Santos (2007) y por Brittos y Lopes (2012) reúnen investigaciones especializadas en políticas de comunicación 
en Brasil; el de Murilo Ramos (2005) aborda políticas públicas vinculadas con el derecho a la comunicación y los derechos sociales; y el de Marques de Melo y Sather (2005) examina los derechos a la comunicación en el contexto de la incipiente sociedad de la información. Específicamente sobre regulación de la televisión, las publicaciones de Jambeiro (2001, 2008) ofrecen un recorrido a lo largo del siglo XX y comienzos del siglo XXI; y Simis (2015) aporta un detallado análisis sobre la economía y la legislación del sector cinematográfico.

En el caso colombiano, la historia de la televisión, su regulación y las relaciones con los distintos gobiernos que se sucedieron en el país han sido estudiadas por Vizcaíno (2004) y Garzón Barreto (2015). Las políticas audiovisuales y los cambios regulatorios desde la década de 1990 fueron abordados por Téllez et al. (2016), mientras que otros trabajos focalizaron en las reformas regulatorias de la segunda década del siglo XXI (García, 2018) y en el análisis de la economía política de las telecomunicaciones (Narváez, 2013).

Sobre el caso uruguayo, los trabajos de Faraone (1989), Kaplún (2007, 2011) y Beltramelli y Kaplún (2017) son una referencia necesaria en los estudios de políticas de medios en este país. Asimismo, las políticas de comunicación en entornos de convergencia han sido estudiadas en términos comparados para los casos de Colombia y Uruguay por Beltramelli, Pérez y Lombana (2018). Varias investigaciones han abordado el desarrollo de las industrias culturales en México (Crovi, 1995, 2013; Gómez, 2008). Algunas de ellas se han enfocado en el análisis de los impactos del Tratado de Libre Comercio de América del Norte sobre el sector audiovisual (Gómez, 2006; Sánchez, 1993).

En Venezuela, los estudios de Guzmán (2003, 2005, 2006) sobre la dimensión económica de las industrias culturales y la industria cinematográfica en el siglo XX, y el de Cañizález (2010) sobre las políticas de medios durante el gobierno de Hugo Chávez, constituyen una referencia obligada. En el caso de Ecuador, los trabajos de Mora (1982) y Ortiz León y Suing (2016) reconstruyen la historia de la televisión, mientras que Isabel Ramos (2012, 2013) analiza la política de comunicación del gobierno de Rafael Correa y su enfrentamiento con los medios privados. En Perú, Gargurevich (1987) y Protzel (2014) ofrecen un panorama acerca de la regulación de los medios de comunicación en el país andino.

También han sido numerosos los trabajos que han abordado las políticas específicas para los medios públicos en América Latina, su función y misión, y el lugar que deberían ocupar en el ecosistema de medios en las sociedades democráticas. En esta línea, el precursor 
trabajo de Pasquali (1991) señalaba los lineamientos para una radiodifusión de servicio público en la región. A lo largo del siglo XXI varias investigaciones se han preguntado por el tránsito de lo estatal a lo público para los medios latinoamericanos y han procurado identificar modelos y fórmulas para que la televisión pública cumpla con la triple misión de “educar, informar y entretener", con sostenibilidad económica, autonomía y contenidos de calidad (Alfaro, 2006; Arroyo et al., 2012; Becerra \& Waisbord, 2015; Guérin et al., 2013; Mastrini, 2011; Fuenzalida, 2000).

Una tercera gran línea de trabajo dentro de las investigaciones de la EPC se vincula con los estudios sobre la estructura de los sistemas de medios, los procesos de concentración de la propiedad y sus efectos en materia de contenidos, pluralismo y diversidad.

En este marco se destacan las investigaciones de Guillermo Mastrini y Martín Becerra en varios países de América Latina sobre los procesos de concentración en cada una de las industrias culturales, incluidas las empresas de telecomunicaciones e internet (Mastrini \& Becerra, 2006; Becerra \& Mastrini, 2009, 2017). En el caso de Brasil, los trabajos de Bolaño (1988, 2000) examinaron el mercado brasilero de televisión, la investigación de Fadul (1998) focalizó en las formas de internacionalización de los grupos de medios en la década de 1990, el trabajo de Brittos (2001) indagó en torno del mercado brasileño de televisión y su expansión transnacional, y el de Bolaño y Brittos (2005) se centró en la hegemonía de la Red Globo. Un estudio más reciente sobre la concentración en este país se halla en Moreira (2016). Los aportes de Sunkel y Geoffroy (2001) acerca del fenómeno de la concentración mediática en Chile también se inscriben en esta línea de investigación, junto con los de Monckeberg (2009), Mayorga, Valle y Nitrihual (2010), Valle et al. (2011) y Godoy (2016). En México, el trabajo de Toussaint (1996) focaliza en la industria televisiva mexicana y sus vínculos con las corporaciones mediáticas de los Estados Unidos, y el de Huerta-Wong y Gómez (2013) brinda precisiones sobre los procesos de concentración de los medios de comunicación y las telecomunicaciones en dicho país.

Asimismo, existen investigaciones que analizan los impactos de la concentración de las industrias culturales sobre la diversidad y el pluralismo en América Latina (Sánchez, 2006); las acciones para medir y fomentar la diversidad cultural en la industria audiovisual, teniendo en cuenta las formas de distribución y exhibición en el pasaje hacia lo digital (Albornoz \& García, 2017); y estudios de caso sobre acceso y diversidad de medios en la Argentina (Califano, Becerra \& Mastrini, 2009) y sobre pluralismo en el mercado 
audiovisual chileno (Anguita \& Labrador, 2019). Algunas investigaciones han procurado analizar de qué modo los intereses económicos de las empresas de medios influyen sobre los contenidos noticiosos. Estos trabajos se preguntan por los efectos de la concentración de la propiedad mediática sobre el comportamiento periodístico y suelen proponer una mirada interdisciplinaria entre la economía política de la comunicación y los estudios sobre el periodismo (Califano, 2015; Koziner, 2016), el análisis del discurso (Califano, 2011), y un enfoque sociológico sobre el comportamiento del "campo político-periodístico" (Archondo, 2003).

Identificamos una cuarta línea de investigación dentro de la EPC latinoamericana en torno de los procesos de movilización social para alcanzar nuevos modos de democratización de la comunicación. Ello incluye el estudio de las diversas formas de activismo y participación ciudadana, junto con la labor y los problemas que enfrentan los medios comunitarios, cooperativos y alternativos.

En esta línea se inscriben una serie de iniciativas regionales identificadas con la comunicación popular y con el derecho a la comunicación. Entre ellas se encuentran la Asociación Latinoamericana de Educación Radiofónica (ALER), luego devenida en una red de radios populares; la Agencia Latinoamericana de Información (ALAI), que conformó una red de comunicación regional y se dedica a la defensa del derecho a la comunicación, la investigación y la capacitación de organizaciones sociales; la Campaña por los Derechos de la Comunicación en la Sociedad de la Información (CRIS), que nació durante la fase preparatoria de la Cumbre Mundial de la Sociedad de la Información (CMSI) en 2002; y la iniciativa regional Internet Ciudadana, que surgió en 2017 bajo el lema "otra internet es posible” y que se halla integrada por diversas organizaciones sociales de América Latina.

Varios han sido los trabajos que han analizado estos movimientos sociales por la democratización de las comunicaciones y por la reforma de las políticas de medios (León, 2013; León, Burch \& Tamayo, 2005; Ramírez \& Burch, 2019; Segura \& Waisbord, 2016; entre otros). De igual modo, existen investigaciones que han abordado el estudio de los medios cooperativos y comunitarios: en el caso argentino, el trabajo coordinado por Monje y Rivero (2018), o el editado por Segura y Weckesser (2016); en Brasil, los trabajos de Peruzzo (2009) sobre movimientos sociales y el de Berti (2018) sobre radios comunitarias; en Bolivia, la investigación de Ramos-Martín (2015) sobre comunicación comunitaria y alternativa y sus procesos de participación e incidencia sobre las políticas públicas, o el 
coordinado por Gumucio y Herrera (2010) sobre radio y televisión comunitaria que abarca también otros casos latinoamericanos; en Colombia, el libro de Téllez (2003) sobre televisión comunitaria; en Chile, los trabajos de Sáez-Baeza $(2013,2020)$ sobre formas de participación ciudadana en distintos procesos de políticas públicas; en Venezuela, las investigaciones de Cañizález (2004) sobre la incidencia de la sociedad civil desde el espacio mediático, el trabajo de Hernández (2009) sobre emisoras comunitarias y alternativas, y el de Gómez y Ramos-Martín (2014) sobre legislación de medios comunitarios en Bolivia y Venezuela; entre otros. En términos de ciudadanía cultural, democracia participativa y políticas de comunicación, el trabajo de Valle (2006) y los libros coordinados por Valle, Moreno y Sierra (2012), y Sierra, Garavante y Leetoy (2018), constituyen una buena referencia.

Una quinta línea de investigación se vincula con las implicancias de la revolución digital y los avances en tecnologías de información y comunicación. Ello abarca el uso y apropiación de tecnologías y medios digitales, y sus impactos sobre las formas de organización, producción y distribución de las industrias culturales y creativas. También podemos ubicar aquí los debates en torno de la "sociedad de la información” y los procesos de globalización.

Las transformaciones en las industrias culturales a partir de la introducción de tecnologías de la información y la comunicación han sido múltiples y variadas. Algunos trabajos enmarcados en la EPC han propuesto diálogos interdisciplinarios fructíferos con los estudios de la sociología del trabajo, a fin de analizar casos específicos de procesos de reorganización productiva y estrategias de readecuación de las industrias culturales (Carboni, 2015; Retegui, 2017). A comienzos del siglo XXI se popularizó la noción de 'industrias creativas', la que incluye y desborda el concepto de industrias culturales al intentar agrupar todas las actividades en las que la creatividad juega un rol central. Varios han sido los trabajos que han examinado y criticado esta noción desde la mirada de la EPC (Garnham, 2005; Schlesinger, 2007; Tremblay, 2011; Zallo, 2016). Con un enfoque crítico, algunas investigaciones se han detenido en el estudio de casos específicos para los sectores comprendidos dentro de las industrias creativas, en particular en Brasil (Ferreira, 2008; Lopes, 2006; Sierra \& Sola, 2020).

Otras investigaciones han procurado abordar los vínculos entre los procesos de globalización y sus efectos sobre las industrias culturales (Sánchez, 2001; Quirós \& Sierra, 2002; Morais \& Jambeiro, 2020; entre otros). También se han publicado reflexiones críticas en torno de 
la llamada "Sociedad de la Información" (Alva, 2015; Becerra, 2003; Crovi, 2004; Charras, 2006; Mastrini \& Califano, 2006; Trejo, 2006); junto con trabajos que analizan los medios digitales y la contribución de las TIC para el desarrollo (Benítez \& Sierra, 2020; Toussaint \& Sierra, 2019). En esta línea se destacan las compilaciones sobre Televisión Digital Terrestre en países de América Latina (Albornoz \& García, 2012; Badillo \& Sierra, 2011), junto con trabajos que estudian los diversos desafíos conceptuales que los procesos de digitalización, la convergencia, la televisión digital, los derechos de autor, la gobernanza global y la regulación de internet conllevan para la elaboración de políticas de comunicación (Mastrini, Bizberge \& Charras, 2013).

Existen múltiples cruces entre las líneas de investigación aquí propuestas, además de abordajes interdisciplinarios en varios de los trabajos reseñados, junto con nuevas problemáticas que permiten continuar ampliando en campo de aplicación de la EPC. Cabe recordar que no se pretende aquí agotar la revisión bibliográfica de la producción latinoamericana de la EPC -que es extensa y continúa incrementándose- sino proponer una sistematización de sus principales líneas de investigación y de algunos de los trabajos representativos de cada una de ellas, en tanto han contribuido a consolidar el campo a fines del siglo XX y a lo largo de las primeras décadas del siglo XXI.

\section{Reflexiones finales}

La Economía Política de la Comunicación consolidó su enfoque a lo largo de la segunda mitad del siglo XX en el estudio de diversos aspectos de los medios e industrias de la comunicación, por medio de la aplicación de conceptos provenientes de la economía, pero también de las ciencias políticas, la historia y la sociología.

Si bien existen diferentes aproximaciones y escuelas dentro de la EPC, en este trabajo hemos desarrollado fundamentalmente la orientación crítica, de raigambre marxista, que sostiene que las industrias y los medios de comunicación cumplen un rol relevante en la producción y reproducción de las relaciones de poder en las sociedades capitalistas. Nos hemos detenido específicamente en el análisis de las investigaciones pioneras en el campo, tanto en América del Norte como en Europa, enfatizando acerca de sus líneas de cruces y diferencias. Desarrollamos, asimismo, los orígenes y la consolidación de la disciplina en América Latina, analizando las investigaciones motorizadas por una serie de intelectuales políticamente comprometidos e imbuidos de una mirada contestataria frente al paradigma de la modernización, dominante en la década de los años sesenta. Estas investigaciones 
denunciaron la dominación cultural que se producía a través de los medios de comunicación y las relaciones existentes entre la propiedad de los medios y la difusión de cierta ideología asociada a sectores de poder. Lograron aportar datos tempranos sobre la estructura de los sistemas de medios en la región y sobre las políticas públicas que encuadraron y promovieron su desarrollo.

A partir de la década de los años noventa, en el contexto de las políticas neoliberales que fomentaron procesos de privatización, concentración, re-regulación y conformación de conglomerados transnacionales de medios, la investigación en América Latina cobró un renovado impulso. Ello fue acompañado por la creación de una serie de asociaciones de investigadores a nivel nacional y regional, junto con el nacimiento iniciativas sociales por el derecho a la comunicación. Desde entonces, varias han sido las líneas de investigación abordadas desde la perspectiva de la EPC latinoamericana. Algunas investigaciones se han enfocado en el estudio de las relaciones sociales en torno de la producción, distribución y consumo de bienes culturales, en la naturaleza contradictoria de dichas relaciones, en las formas cambiantes de la propiedad y el control de los medios y recursos de la comunicación, y en el modo en que ello puede llegar a incidir sobre los contenidos mediáticos. Otros trabajos han indagado sobre la estructura de los mercados, la expansión internacional de las corporaciones de medios y sus vínculos con sectores económicos y financieros; los diversos impactos de la economía sobre la comunicación y la cultura; la incidencia que ha tenido el desarrollo de las tecnologías de información y comunicación en los procesos de producción, consumo y distribución de las industrias culturales; las políticas públicas de comunicación y cultura, sus procesos de elaboración y los modos de intervención del Estado; los mecanismos que debilitan la existencia de sociedades democráticas y las posibles formas de resistencia de la sociedad civil, entre otros.

En este trabajo propusimos una sistematización de las líneas de investigación principales desde la mirada de la EPC latinoamericana: la teoría, la epistemología y los métodos de la Economía Política de la Comunicación; el análisis de las políticas de comunicación y cultura, así como las políticas específicas para los medios públicos; los estudios sobre la estructura de los sistemas de medios, los procesos de concentración de la propiedad y sus efectos en materia de contenidos, pluralismo y diversidad; los procesos de movilización social y las diversas formas de activismo y participación ciudadana para alcanzar nuevos modos de democratización de la comunicación; y las implicancias de los procesos de digitalización y los desarrollos en tecnologías de información y comunicación sobre las industrias culturales. 
La variedad de problemáticas abordadas desde la EPC ha ido ampliándose desde sus orígenes, y ha establecido cruces con otras ramas de la comunicación y con otros enfoques y disciplinas, en un intento por realizar análisis holísticos de los medios de comunicación. No obstante, la esencia de los trabajos enmarcados en la escuela crítica preserva el énfasis de los estudios iniciales en la pregunta por las relaciones de poder en los procesos de producción, distribución y consumo de bienes y recursos comunicacionales, aunque en un contexto distinto y ampliado, atravesado por procesos de transformación constante de los sistemas de medios, que conllevan renovados desafíos y preocupaciones.

\section{Conflicto de interés}

La autora declara que no tiene conflicto de interés. 


\section{Referencias bibliográficas}

ALBORNOZ, L. (2000): Al fin solos... La nueva televisión del Mercosur. Buenos Aires, Ciccus - La Crujía.

ALBORNOZ, L., \& GARCÍA, M. T. (Eds.) (2012): La Televisión Digital Terrestre. Experiencias nacionales y diversidad en Europa, América y Asia. Buenos Aires, La Crujía.

(Eds.) (2017): Diversidad e industrias audiovisuales: El desafío cultural del siglo XXI. México D.F., Fondo de Cultura Económica.

ALFARO, R. M. (Ed.) (2006): De lo estatal a lo público. Medios: ¿de quién y para qué? Lima, A.C.S Calandria y Veeduría Ciudadana de la Comunicación Social.

ALTAMIRANO, F. (2021): Intelectuales, exilio y comunicación en el Instituto Latinoamericano de Estudios Transnacionales (ILET) (1975-1984). Revista de la Red de Intercátedras de Historia de América Latina Contemporánea, 7(13), pp. 250278.

ALTHUSSER, L. (1967): Contradicción y sobredeterminación. En L. Althusser, La revolución teórica de Marx. Buenos Aires, Siglo XXI.

(1970): Ideología y aparatos ideológicos del Estado. Buenos Aires, Nueva Visión.

ALVA, A. R. (2015): Los nuevos rostros de la desigualdad en el siglo XXI: la brecha digital. Revista Mexicana de Ciencias Políticas y Sociales, 6o(223), pp. 265-285.

ANGUITA, P. \& LABRADOR, M. J. (2019): Pluralismo y libre competencia en el mercado de la televisión y radiodifusión: el caso chileno. Revista de Comunicación, 18(1), pp. 930 .

ARCHONDO, R. (2003): Incestos y blindajes. Una radiografía del juego políticoperiodístico. La Paz, Plural.

ARGUMEDO, A. (1987): Breve reseña cronológica del debate internacional sobre el Nuevo Orden Mundial de la Información y las Comunicaciones. En A. Argumedo, Los laberintos de la crisis. América Latina: poder transnacional y comunicaciones (pp. 259-291). Buenos Aires, Puntosur - ILET.

ARROYO, L., BECERRA, M., GARCÍA, Á., \& SANTAMARÍA, O. (2012): Cajas mágicas. El renacimiento de la televisión pública en América Latina. Madrid, Tecnos.

BADILLO, Á., \& SIERRA, F. (Coords.) (2011): La transición a la televisión digital terrestre 
en Iberoamérica: diagnóstico y prospectiva. Quito (Ecuador), CIESPAL.

BADILLO, Á., MASTRINI, G., \& MARENGHI, P. (2015): Teoría crítica, izquierda y políticas públicas de comunicación: el caso de América Latina y los gobiernos progresistas. Comunicación y Sociedad, (24), pp. 95-126.

BALADRÓN, M. (2007): La política de comunicación del gobierno de Eduardo Duhalde [Tesis de grado, Carrera de Ciencias de la Comunicación, Universidad de Buenos Aires].

BECERRA, M. \& MASTRINI, G. (2009): Los dueños de la palabra. Acceso, estructura y concentración de los medios en la América latina del siglo XXI. Buenos Aires, Prometeo.

(2017): La concentración infocomunicacional en América Latina (200o-2015). Nuevos medios y tecnologías, menos actores. Bernal, Universidad Nacional de Quilmes - Observacom.

BECERRA, M. \& WAISBORD, S. (2015): Principios y "buenas prácticas" para los medios públicos en América Latina. Montevideo, UNESCO.

BECERRA, M. (2003): Sociedad de la información: proyecto, convergencia, divergencia. Buenos Aires, Grupo Editorial Norma.

(2015): De la concentración a la convergencia. Políticas de medios en Argentina y América Latina. Buenos Aires, Paidós.

BECERRA, M., \& MASTRINI, G. (2006): Senderos de la economía de la comunicación: un enfoque latinoamericano. CIC Cuadernos de Información y Comunicación, 11, pp. 111-128.

BELTRAMELLI, F. \& KAPLÚN, G. (2017): Políticas de comunicación en Uruguay: el país de la doble escena. Cartagena, IAMCR.

BELTRAMELLI, F., PÉREZ, D. \& LOMBANA, D. (2018): Políticas de comunicación y medios en entornos de convergencia en América Latina: una aproximación a los casos de Uruguay y Colombia. Correspondencias \& Análisis, 254(8), pp. 239-254.

BELTRÁN, L. R. \& FOX, E. (1980): Comunicación dominada: Estados Unidos en los medios de América Latina. México D.F., Instituto Latinoamericano de Estudios Transnacionales/Nueva Imagen.

BELTRÁN, L. R. (1974): Las políticas nacionales de la comunicación en América Latina. Paris, UNESCO. 
BENÍTEZ, L. \& SIERRA, F. (2020): TIC y comunicación para el desarrollo. Madrid, UOC.

BERTI, O. M. (2018): Rádios comunitárias brasileiras: lições e reflexões dos novos e diferenciais mapas do poder e das ações coletivas para a América Latina. En M. J. Baldessar \& D. I. Monje (Eds.), Diálogos latino-americanos: comunicação e democracia em tempos de convergência (pp. 207-229). Sao Paulo, Intercom.

BIZBERGE, A. (2017): Los desafios de la convergencia digital para las politicas de comunicación. En C. Labate \& C. Arrueta (Eds.), La comunicación digital. Redes sociales, nuevas audiencias y convergencia (pp. 19-38). San Salvador de Jujuy, Ediunju - Fadeccos.

BOLAÑO, C. (1988): Mercado Brasileiro de Televisão. Aracaju, UFS.

(2000): Indústria Cultural, Informação e Capitalismo. Sao Paulo, Editora Hucitec Editora Polis.

(Org.) (2012): Comunicación y la Crítica de la Economía Política. Perspectivas teóricas y epistemológicas. Quito (Ecuador), CIESPAL.

BOLAÑO, C., \& BRITTOS, V. C. (Orgs.) (2005): Rede Globo: 40 anos de poder e hegemonia. Sao Paulo, Paulus.

BOLAÑO, C., \& MASTRINI, G. (2002): Economía Política de la Comunicación: un aporte marxista a la constitución del campo comunicacional. Oficios Terrestres, (11-12), pp. $45-55$.

BOLAÑO, C., MASTRINI, G. \& SIERRA, F. (2005): Economía política, comunicación y conocimiento. Una perspectiva crítica latinoamericana. Buenos Aires, La Crujía.

BOLAÑO, C., NARVÁEZ, A. \& LOPES, R. (2014): Economía política de la información, la comunicación y la cultura. En C. Bolaño, D. Crovi \& G. Cimadevilla (Eds.), La contribución de América Latina al campo de la Comunicación (pp. 498-524). La Paz, GRC - ALAIC.

BRITTOS, V. C. \& LOPES, R. S. (2012): Políticas de Comunicação e Sociedade. Sao Paulo, Intercom.

BRITTOS, V. C. (2001): Capitalismo contemporâneo, mercado brasileiro de televisão por assinatura e expansão transnacional [Tesis de Doctorado en Comunicación y Cultura Contemporánea, Universidad Federal de Bahía, Brasil].

CALIFANO, B. (2009): Medios y políticas de comunicación en Argentina bajo el gobierno de Néstor Kirchner (2003-2007). Buenos Aires, Secretaría de Cultura de la Presidencia de la Nación. 
(2011): "Queremos los medios en manos de empresarios nacionales". Un análisis del discurso de Néstor Kirchner en la prensa escrita. Ecos de la comunicación, 4(4), pp. 11-38.

(2014): Políticas de comunicación en la Argentina. Estudio del proceso privatizador de los canales de televisión 11 y 13 de la Ciudad de Buenos Aires [Tesis de Doctorado, Facultad de Ciencias Sociales, Universidad de Buenos Aires, Argentina].

(2015): Los medios de comunicación, las noticias y su influencia sobre el sistema político. Revista Mexicana de Opinión Pública, (19), pp. 61-78.

(2017): En nombre de la convergencia: cambios en la política de regulación de las TIC en Argentina. Estudos em comunicação - Communication Studies, (24), pp. 1-25.

(2019): Urgencias públicas e intereses privados: la regulación de medios en la agenda del gobierno argentino (2015-2019). Ensambles, 6(11), pp. 72-90.

CALIFANO, B., BECERRA, M. \& MASTRINI, G. (2009): Principles for a public interest communications environment: access and content diversity in Argentina. London, Association for Civil Rights - Global Partners \& Associates.

CAÑIZÁLEZ, A. (2004): Sociedad civil, medios y política en Venezuela: Una mirada a su interacción. En D. Mato (Ed.), Políticas de ciudadanía y sociedad civil en tiempos de globalización (pp. 151-166). Caracas, FACES, Universidad Central de Venezuela.

(2010): Medios, Gobernabilidad Democrática y Políticas Públicas. La Presidencia Mediática: Hugo Chávez (1999-20o9) [Tesis de Doctorado en Ciencia Política, Universidad Simón Bolívar, Venezuela].

CAPPARELLI, S. (1999): Enfim, Sos: a nova televisao no cone sul. Porto Alegre, L\&PM.

CAPRILES, O. (1976): El Estado y los medios de comunicación en Venezuela. Caracas, UCV.

CARBONI, O. (2015): Los procesos de organización productiva y del trabajo en las tiras diarias de la televisión abierta argentina (2002-2012) [Tesis de Doctorado en Ciencias Sociales, Facultad de Ciencias Sociales, Universidad de Buenos Aires, Argentina].

CHARRAS, D. (2006): Redes, burbujas y promesas. Algunas reflexiones críticas acerca del proyecto Sociedad de la Información y la nueva economía. Buenos Aires, Prometeo.

CROVI, D. (1995): Desarrollo de las industrias audiovisuales en México y Canadá. México D.F., Facultad de Ciencias Políticas y Sociales. 
(2013): Industrias culturales en México: reflexiones para actualizar el debate. México D.F., Universidad Nacional Autónoma de México.

(Coord.) (2004): Sociedad de la información y el conocimiento: entre lo falaz y lo posible. Buenos Aires, La Crujía.

DORFMAN, A. \& MATTELART, A. (2002): Para leer al Pato Donald. Comunicación de masa y colonialismo. Buenos Aires, Siglo XXI.

EXENI, J. L. (1998): Las PNC: latinoamericano atrevimiento. En J. L. Exeni, Políticas de comunicación. La Paz, Fundación Plural.

FADUL, A. (1998): A internacionalização da mídia brasileira. Comunicação e Sociedade, (29), pp. 67-91.

FARAONE, R. (1989): Estado y T.V. en el Uruguay. Montevideo, Fundación de Cultura Universitaria.

FERREIRA, F. (2008): Cities, the Information Society and the Creative Industries: an analysis of the core media related creative industries in Salvador, Bahia [Tesis de Doctorado, Universidad de Texas en Austin, Estados Unidos].

FLICHY, P. (1980): Las multinacionales del audiovisual. Barcelona, Gustavo Gili.

FUENZALIDA, V. (2000): La televisión pública en América Latina: reforma o privatización. México D.F., Fondo de Cultura Económica.

GARCÍA, D. (2018): Políticas audiovisuales en Colombia (2010-2017). La convergencia tecnológica contra la independencia del ente regulador. En Memorias del XIV Congreso de la Asociación Latinoamericana de Investigadores de la Comunicación. San Pedro, Costa Rica.

GARGUREVICH, J. L. (1987): Prensa, radio y televisión: una historia crítica. Lima, Horizonte.

GARNHAM, N. (1979): Contribution to a political economy of mass-communication. Media, Culture \& Society, 1, pp. 123-146.

(2005): From cultural to creative industries. An analysis of the implications of the "creative industries" approach to arts and media policy making in the United Kingdom. International Journal of Cultural Policy, 11(1), pp. 15-29.

GARZÓN, J. C. (2015): Televisión y Estado en Colombia 1954-2014. Bogotá, Universidad Externado de Colombia. 
GETINO, O. (1995): Las industrias culturales en la Argentina. Dimensión económica y políticas públicas. Buenos Aires, Colihue.

(2000): Las industrias culturales del Mercosur. Buenos Aires, Observatorio de Industrias Culturales (OIC) de la Ciudad de Buenos Aires.

GODOY, S. (2016): Media Ownership and Concentration in Chile. En E. M. Noam (Ed.), Who owns the world's media? Media Concentration and Ownership around the World (pp. 641-668). New York, Oxford University Press.

GÓMEZ, A. M. \& RAMOS, J. (2014): Legislación y medios comunitarios. Análisis comparativo de Bolivia y Venezuela. Palabra Clave, 17(2), pp. 484-516.

GÓMEZ, R. (2006): El impacto del Tratado de Libre Comercio de América del Norte en la industria audiovisual mexicana (1994-2002) [Tesis de Doctorado, Universidad Autónoma de Barcelona, España].

(2008): Políticas e industrias audiovisuales en México. Comunicación y Sociedad. Nueva época, (10), pp. 191-223.

GRAZIANO, M. (1974): Los dueños de la televisión argentina. Comunicación y Cultura, (3), pp. 175-212.

(1997): Guía teórica 1era parte. Buenos Aires, Facultad de Ciencias Sociales, Universidad de Buenos Aires.

GUÉRIN, A. I., MIRANDA, A., OLIVIERI, R. \& SANTAGATA, G. (Comp.) (2013): Pensar la televisión pública: ¿Qué modelos para América Latina? Buenos Aires, La Crujía.

GUMUCIO, A., \& HERRERA, K. (Coords.) (2010): Políticas y legislación para la radio local en América Latina. La Paz, Plural.

GUZMÁN, C. (2003): Políticas y Economía de la Cultura en Venezuela. Una estimación del comportamiento productivo de las industrias y actividades relacionadas con el sector cultural venezolano. Cuadernos ININCO, 1(25), pp. 225-270.

(2005): Las industrias culturales en la economía de Venezuela y su contribución al PIB 1997-2002. Anuario ININCO, 17(2), pp. 191-216.

(2006): La industria cinematográfica y su consumo en los países de Iberoamérica. Un análisis comparativo diacrónico. Anuario ININCO, 18(1).

HALL, S. (1977): Culture, the Media and the Ideological Effect. En J. Curran, M. Gurevitch, \& J. Woollacott (Eds.), Mass-Communication and Society. London: Edward Arnold. 
HAUSSEN, D. F. \& BRITTOS, V. C. (2009): Economia política, comunicaçao e cultura: aportes teoricos e temas emergentes na agenda politica brasileira. Porto Alegre, EDIPUCRS.

HERNÁNDEZ, D. (2009): Sobre la naturaleza de las "emisoras de radiodifusión sonora y televisión abierta comunitarias de servicio público sin fines de lucro". En S. Sel (Comp.), La comunicación mediatizada: hegemonías, alternatividades, soberanías (pp. 39-59). Buenos Aires, CLACSO.

HERSCOVICI, A. (1995): Economia da cultura e da comunicaçao. Vitória, Editora UFES.

HUERTA-WONG, J. E. \& GÓMEZ, R. (2013): Concentración y diversidad de los medios de comunicación y las telecomunicaciones en México. Comunicación y sociedad, (19), pp. 113-152.

JAMBEIRO, O. (2000): Regulando a TV: uma visão comparativa no Mercosul. Salvador, EdUFBA. (2001): A TV no Brasil do século XX. Salvador da Bahia, Edufba.

(2008): A Regulação da TV no Brasil: 75 anos depois, o que temos? Estudos de Sociologia, 13(24), pp. 85-104.

KAPLÚN, G. (2007): Políticas de comunicación. Cambios y resistencias. Fronteiras estudos midiáticos, 9(1), pp. 5-11.

(2011): Políticas de comunicación en Uruguay: agenda pendiente y agenda pública. Derecho a comunicar, 1(1), pp. 35-51.

KOZINER, N. S. (2016): La prensa económica y el debate sobre los medios: análisis de la cobertura informativa del proceso de discusión de la Ley de Servicios de Comunicación Audiovisual en Ámbito Financiero y El Cronista Comercial (marzooctubre de 2009) [Tesis de Doctorado, Universidad Nacional de Quilmes, Argentina].

LEÓN, O. (Coord.) (2013): Democratizar la palabra. Movimientos convergentes en comunicación. Quito (Ecuador), ALAI.

LEÓN, O., BURCH, S. \& TAMAYO, E. (2005): Movimientos sociales y comunicación. Quito (Ecuador), ALAI.

LOPES, R. S. (2006): Uma nova agenda para a cultura: o discurso da economia criativa no governo Rousseff. En A. Rubim, A. Barbalho, \& L. Calabre (Eds.), Políticas culturais no governo Dilma (pp. 173-199). Salvador, EDUFBA. 
MACBRIDE, S. (1980): Un solo mundo, voces múltiples. Comunicación e información en nuestro tiempo. México D.F., Fondo de Cultura Económica.

MARINO, S. (2012): Políticas de comunicación del sector audiovisual: las paradojas de modelos divergentes con resultados congruentes. Los casos de la Televisión por Cable y el Cine en Argentina entre 1989-2007 [Tesis de Doctorado, Facultad de Ciencias Sociales, Universidad de Buenos Aires, Argentina].

MARQUES, J. \& SATHER, L. (2005): Direitos à Comunicação na Sociedade da Informação. São Paulo, UMESP.

MARQUES, J. (1993): Communication for a new world: Brazilian perspectives. Sao Paulo, ECA-USP.

MARX, K. \& ENGELS, F. ([1845] 1982): La ideología alemana. La Habana, Pueblo y Educación.

MARX, K. ([1859] 2008a): Contribución a la crítica de la Economia Política (9a ed.). Buenos Aires, Siglo XXI.

([1867] 2008b): El capital. Tomo I: El proceso de producción del capital. México D.F., Siglo XXI.

MASTRINI, G. (2011): Medios públicos y derecho a la comunicación: una aproximación desde América Latina [Archivo PDF]. Portal de la Comunicación InCom-UAB. https://incom.uab.cat/portalcom/medios-publicos-y-derecho-a-la-comunicacionuna-aproximacion-desde-america-latina/?lang=es

MASTRINI, G. \& BECERRA, M. (2006): Periodistas y Magnates. Estructura y concentración de las industrias culturales en América Latina. Buenos Aires, Prometeo.

(Eds.) (2017): Medios en guerra. Balance, crítica y desguace de las políticas de comunicación 2003-2016. Buenos Aires, Biblos.

MASTRINI, G. \& CALIFANO, B. (Eds.) (2006): Sociedad de la información en la Argentina: políticas públicas y participación social. Buenos Aires, Friedrich Ebert Stiftung.

MASTRINI, G. (2013): Las industrias culturales en Argentina. Economía y política del sector audiovisual en la década del ' 90 [Tesis de Doctorado, Facultad de Ciencias de la Información, Universidad Complutense de Madrid, España].

(Ed.) (2009): Mucho ruido, pocas leyes. Economía y políticas de comunicación en la Argentina (1920-2007) (2da ed.). Buenos Aires, La Crujía. 
MASTRINI, G., \& BOLAÑN, C. (1999): Globalización y monopolios en la comunicación en América Latina. Hacia una economía política de la comunicación. Buenos Aires, Biblos.

MASTRINI, G., BIZBERGE, A. \& CHARRAS, D. (Eds.) (2013): Las políticas de comunicación en el siglo XXI. Nuevos y viejos desafios. Buenos Aires, La Crujía.

MAYORGA, A. J., VALLE, C. \& NITRIHUAL, L. (2010): Concentración de la propiedad de los medios de comunicación en Chile. La compleja relación entre oligopolio y democracia. Anagramas - Rumbos y sentidos de la comunicación, 9(17), pp. 131148.

MIÈGE, B. (1987): The logics at work in the new cultural indutries. Media, Culture and Society, 9, pp. 273-289.

MILIBAND, R. (1977): Marxism and politics. Oxford, Oxford University Press.

MILLER, K. M. \& GANDY, O. H. (1991): Paradigmatic Drift: A Bibliographic Review of the Spread of Economic Analysis in the Literature of Communication. Journalism \& Mass Communication Quarterly, 68(4), pp. 663-671.

MONCKEBERG, M. O. (2009): Los magnates de la prensa: Concentracion de los medios de comunicacion en Chile. Santiago (Chile), Debate.

MONJE, D. I. \& RIVERO, E. (Comp.) (2018): Televisión Cooperativa y Comunitaria: diagnóstico, análisis y estrategias para el sector no lucrativo en el contexto convergente. Córdoba, Cooperativa de Trabajo El Zócalo.

MONJE, D. I. (2013): Políticas del audiovisual en el marco de la integración regional mercosureña. Período 1991-2007 [Tesis de Doctorado, Facultad de Periodismo y Comunicación Social, Universidad Nacional de La Plata, Argentina].

MORA, A. L. (1982): La televisión en el Ecuador. Guayaquil, Editorial Amauta.

MORAIS, K. \& JAMBEIRO, O. (2020): Por uma economia política do audiovisual no capitalismo global. Revista Eptic, 22(3), pp. 185-204.

MOREIRA, S. (2016): Media Ownership and Concentration in Brazil. En E. M. Noam, Who owns the world's media? Media Concentration and Ownership around the World (pp. 606-633). New York, Oxford University Press.

MOSCO, V. (2009): La economía política de la comunicación. Barcelona, Bosch.

MURARO, H. (1973a): La manija: ¿quiénes son los dueños de los medios de comunicación en América Latina? Crisis, (1), pp. 48-53. 

(1973b): La manija (II): Los dueños de la televisión argentina. Crisis, (2), pp. 52-60. (1974): Neocapitalismo y comunicación de masa. Buenos Aires, Eudeba. (1987): Invasión cultural, economía y comunicación. Buenos Aires, Legasa.

MURDOCK, G. \& GOLDING, P. (1973): For a Political Economy of Mass Communications. Socialist Register, 10, pp. 205-234.

(1981): Capitalismo, comunicaciones y relaciones de clase. En J. Curran (Ed.), Sociedad y comunicación de masas (pp. 22-57). México D.F., Fondo de Cultura Económica.

MURDOCK, G. (1978): Blindspots about Western Marxism: a reply to Dallas Smythe. Canadian Journal of Political and Social Theory, 2(2), pp. 109-119.

NARVÁEZ, A. (2013): Mercado y consumo: economía política de las telecomunicaciones en Colombia. Campos en Ciencias Sociales, 1(2), pp. 231.

ORTIZ, C. \& SUING, A. (2016): La televisión ecuatoriana: pasado y presente. Razón y Palabra, 93, pp. 135-152.

PASQUALI, A. (1976): Comunicación y cultura de masas. Caracas, Monte Ávila. (1991): ¿Qué es una radiodifusión de servicio público? En A. Pasquali, El orden reina. Caracas, Monte Ávila.

PERUZZO, C. (2009): Movimentos sociais, cidadania e o direito à comunicação comunitária nas políticas. Fronteiras - estudos midiáticos, 11(1), pp. 33-44.

PROTZEL, J. (2014): Media Systems and Political Action in Peru. En M. A. Guerrero \& M. Márquez-Ramírez (Eds.), Media Systems and Communication Policies in Latin America (pp. 82-99). New York, Palgrave Macmillan.

QUIRÓS, F. \& SIERRA, F. (2002): Comunicación, globalización y democracia. Crítica de la Economía Política de la Comunicación y la Cultura. Sevilla (España), Comunicación Social, Ediciones y Publicaciones.

RAMÍREZ, H. \& BURCH, S. (2019): Contribuciones y experiencias de la comunicación desde América Latina y Caribe. Chasqui. Revista Latinoamericana de Comunicación, 1(141), pp. 87-104. https://doi.org/10.16921/chasqui.voi141.4087

RAMOS, I. (2012): La contienda política entre los medios privados y el gobierno de Rafael Correa. Utopía y Praxis Latinoamericana, 17(58), pp. 65-76. (2013): Trayectorias de democratización y desdemocratización de la comunicación en 
Ecuador. Íconos - Revista de Ciencias Sociales, o(46), pp. 67-82.

RAMOS, M. C. \& DOS-SANTOS, S. (2007): Políticas de comunicação: buscas teóricas e práticas. Sao Paulo, Paulus.

RAMOS, M. C. (2005): Comunicação, Direitos Sociais e Políticas Públicas. En J. Marques de Melo \& L. Sather (Eds.), Direito à Comunicação na Sociedade da Informação (pp. 245-253). Sao Paulo, UMESP.

RAMOS-MARTÍN, J. (2015): La revolución de los desheredados. Participación de las redes de medios comunitarios y alternativos en la construcción de políticas de comunicación en Bolivia [Tesis de Doctorado, Estado de Derecho y Gobernanza Global, Universidad de Salamanca, España].

RETEGUI, L. (2017): Los procesos de organización del trabajo en la redacción de un diario. Un estudio a partir del diario La Nación, en el contexto digital (1995-2013) [Tesis Doctoral en Ciencias Sociales y Humanas, Universidad Nacional de Quilmes, Argentina].

REYES, F. (Ed.) (1977): La información en el nuevo orden internacional. México D.F., ILET.

RONCAGLIOLO, R. (1983): Comunicación y democracia en el debate internacional. Revista Chasqui, (7), pp. 46-52.

SÁEZ-BAEZA, C. (2013): Políticas públicas de comunicación y participación ciudadana: el caso de la televisión digital en Chile. Signo y Pensamiento, XXXII(63), pp. 34-51.

(2020): \#ChileDespertó: participación ciudadana y malestar en el ámbito de las políticas de radiodifusión y telecomunicaciones (2014-2018). Revista de la Asociación Española de Investigación de la Comunicación, 7(13), pp. 2-23.

SÁNCHEZ, E. (1993): El espacio audiovisual mexicano ante el acuerdo de libre comercio Canadá-Estados Unidos-México. Intercom Revista Brasileira de Ciências da Comunicação, 16(1), pp. 34-48.

(2001): Globalización y convergencia: retos para las industrias culturales latinoamericanas. Escribanía, (6), pp. 57-71.

(2006): Industrias culturales, diversidad y pluralismo en América Latina. CIC Cuadernos de información y comunicación, 11, pp. 207-221.

SCHILLER, H. I. (1976): Comunicación de masas e imperialismo yanqui. Barcelona, Gustavo Gili.

SCHLESINGER, P. (2007): Creativity: from discourse to doctrine? Screen, 48(3), pp. 377387. 
SEGURA, M. S., \& WAISBORD, S. (2016): Media Movements. Civil society and Media Policy Reform in Latin America. London, ZED Books.

SEGURA, M. S., \& WECKESSER, C. (Ed.) (2016): Los medios sin fines de lucro entre la Ley Audiovisual y los decretos. Estrategias, desafios y debates en el escenario 20092015. Córdoba, Secretaría de Ciencia y Técnica, Universidad Nacional de Córdoba.

SEL, S. (Coord.) (2010): Políticas de comunicación en el capitalismo contemporáneo. Buenos Aires, CLACSO.

SIERRA, F. \& SOLA, S. (2020): Políticas de Comunicación y Economía Creativa. El reto de la cultura y el desarrollo local. Sevilla (España), Comunicación Social. Ediciones y Publicaciones.

SIERRA, F. \& VALLEJO, R. E. (Coords.) (2017): Derecho a la comunicación. Procesos regulatorios y democracia en América Latina. Quito (Ecuador), Ediciones CIESPAL.

SIERRA, F., GARAVANTE, T. \& LEETOY, S. (Coords.) (2018): Ciudadanía digital y democracia participativa. Sevilla (España), Comunicación Social. Ediciones y Publicaciones.

SIMIS, A. (2015): Estado e cinema no Brasil. Sao Paulo, UNESP.

SMITH, A. ([1776] 1996): La riqueza de las naciones. Madrid, Alianza.

SMYTHE, D. W. (1960): On the Political Economy of Communications. Journalism \& Mass Communication Quarterly, 37(4), pp. 563-572. (1977): Communications: blindspot of Western Marxism. Canadian Journal of Political and Social Theory, 1(3), pp. 1-27.

(1978): Rejoinder to Graham Murdoch. Canadian Journal of Political and Social Theory, 2(2), pp. 120-127.

SOMAVÍA, J. (1978): La comunicación y el modelo transnacional de desarrollo. Nueva Sociedad, (38), pp. 32-41.

SUNKEL, G. \& GEOFFROY, E. (2001): Concentración económica de los medios de comunicación. Santiago (Chile), LOM Ediciones.

TÉLlEZ, M. P. (2003): La televisión comunitaria en Colombia. Entre la realidad y la utopía. Bogotá, Ministerio de Cultura, CNTV. 
TÉLLEZ, M. P., PÉREZ, D., CALA, L. C. \& POLO, N. D. (2016): Políticas de comunicación y cultura en Colombia. Convergencias y divergencias. Bogotá, Ministerio de Cultura - Pontificia Universidad Javeriana.

TOUSSAINT, F. \& SIERRA, F. (Coords.) (2019): Economía política y medios digitales. Sevilla (España), Comunicación Social. Ediciones y Publicaciones.

TOUSSAINT, F. (1996): La industria televisiva de México en su vínculo con las corporaciones de medios de Estados Unidos [Tesis de Doctorado, Facultad de Ciencias Políticas y Sociales, Universidad Nacional Autónoma de México, México].

TREJO, R. (2006): Viviendo en El Aleph. La sociedad de la información y sus laberintos. Barcelona, Gedisa.

TREMBLAY, G. (2011): Industrias culturales, economía creativa y sociedad de la información. En L. Albornoz (Ed.), Poder, medios, cultura. Una mirada crítica desde la economía política de la comunicación (pp. 109-138). Buenos Aires, Paidós.

VALLE, C. (2006): Comunicación Participativa, Estado-Nación y Democracia. Discurso, tecnología y poder. Temuco, Ediciones Universidad de La Frontera.

VALLE, C., MELLADO, C., SALINAS, P. \& GONZÁLEZ, G. (2011): La concentración de la propiedad de los medios de comunicación en Chile. De la propiedad al mercado de la publicidad: Los desafíos pendientes. Sapiens. Revista Universitaria de Investigación, 12(1), pp. 44-58.

VALLE, C., MORENO, F. J. \& SIERRA, F. (Coords.) (2012): Políticas de comunicación y ciudadanía cultural iberoamericana. Barcelona, Gedisa.

VIZCAÍNO, M. (2004): La legislación de televisión en Colombia: entre el Estado y el mercado. Historia Crítica, (28), pp. 127-144.

WASKO, J. (2005): Studying the political economy of media and information. Comunicação e Sociedade, 7, pp. 25-48.

WILLIAMS, R. (1973): Base and Superstructure in Marxist Cultural Theory. New Left Review, I(82), pp. 3-16. (1977): Marxism and literature. Oxford, Oxford University Press. 